\title{
Rainfall-landslide early warning system (RLEWS) using TRMM precipitation estimates
}

\author{
Norsuzila Ya'acob ${ }^{1}$, Noraisyah Tajudin ${ }^{2}$, Aziean Mohd Azize ${ }^{3}$ \\ 1,2Faculty of Electrical Engineering, Universiti Teknologi MARA, 404500 Shah Alam Selangor, Malaysia \\ ${ }^{1}$ Wireless Communication Technology (WiCoT), Faculty of Electrical Engineering, UniversitiTeknologi MARA, \\ 404500 Shah Alam Selangor, Malaysia \\ ${ }^{3}$ Universiti Teknikal Malaysia Melaka, 76100 Durian Tunggal, Melaka
}

\begin{tabular}{|c|c|}
\hline Article Info & ABSTRACT \\
\hline Article history: & \multirow{11}{*}{$\begin{array}{l}\text { This paper presents Rainfall-Landslide Early Warning System (RLEWS) } \\
\text { using Tropical Rainfall Measuring Mission (TRMM) precipitation estimates } \\
\text { to notify the warning level for the possibility of landslide occurrences in Ulu } \\
\text { Kelang, Selangor. In this study, RLEWS is developed to monitor the } \\
\text { possibility of rainfall-induced landslide occurrences by comparing real time } \\
\text { TRMM rainfall data with a landslide rainfall threshold. The landslide rainfall } \\
\text { threshold is constructed by using the accumulated rainfall-accumulated } \\
\text { rainfall (E-E) diagram method. The warning levels of rainfall threshold are } \\
\text { classified into three levels; high, moderate and low. The analysis and } \\
\text { notification are updating every } 24 \text { hours to provide the initial potential } \\
\text { landslide information signal. The rainfall threshold analysis was able to } \\
\text { detect the early signal of initial potential landslide occurrences. The aims of } \\
\text { this study are to develop a low-cost, sustainable early warning system and } \\
\text { web base application to send notification and awareness for residential areas } \\
\text { in Ulu Kelang, Selangor. }\end{array}$} \\
\hline Received Sep 15, 2018 & \\
\hline Revised Nov 30, 2018 & \\
\hline Accepted Dec 20, 2018 & \\
\hline & \\
\hline Keywords: & \\
\hline Early warning system & \\
\hline Landslide & \\
\hline Rainfall threshold & \\
\hline Remote sensing & \\
\hline TRMM & \\
\hline
\end{tabular}

Copyright @ 2019 Institute of Advanced Engineering and Science. All rights reserved.

\section{Corresponding Author:}

Norsuzila Ya'acob, Faculty of Electrical Engineering, Universiti Teknologi MARA, 404500 Shah Alam Selangor, Malaysia.

Email: norsuzila@salam.uitm.edu.my

\section{INTRODUCTION}

Landslides are defined as the movement of a mass of rock, debris or earth down slope influence by gravity. The often triggering factors of landslide including intense or prolonged rainfall, earthquakes, rapid snow melting, volcanic activity and variety of anthropogenic activities. Landslide disaster may affect on human life, property and the environment [1]-[3]. In Malaysia, most of landslides or slope failure incident occurred due to intense rainfall and urban development over hillside areas [4]. On 6th December 2008, a landslide was occurred at Taman Bukitn Mewah, Bukit Antarabangsa, Ulu Kelang, Selangor. This tragedy claimed the lives of four people with 15 others injured. It was estimated that 101,500 cubic meters of earth had translated, represents one of the major landslide phenomena that occurred in Ulu Kelang Selangor. An early warning system is capable to reduce or minimize the impact of landslide occurences on human, property damage and loss of live [5], [6].

Rainfall thresholds are widely used in the development of landslide Early Warning System (EWS) at regional scale. This method is able to provide better results than the physically based method [7]-[9]. Empirical thresholds for critical rainfall, either daily or hourly and antecedent rainfall, which is triggering the landslide is developed from accessing data of date, time and rainfall data for the prior landslide events. The term "threshold" is defined as the minimum or maximum level of a number of quantities needed for a process of take place or a state of change. For rainfall-induced landslides, a rainfall threshold is referring to the 
amount of rainfall that, when reached or exceeded, is likely to trigger landslides. Rainfall threshold can be classified into five categories including intensity-duration (ID diagram), accumulated rainfall-duration (R-D diagram), Accumulated rainfall, intensity-accumulated rainfall (I-R diagram) and accumulated rainfall accumulated rainfall (R-R diagram) [10]-[12].

There are many approaches for rainfall threshold analysis, its including the use of gauge-based rainfall data to examine the relationship between rainfall and landslide occurrence. However, this method provides a limited rainfall data because of the limited number and accessibility of the rain gauge station and some rainfall data is based on monthly accumulation reading [13]-[16]. Therefore, the approaches using the remote sensing imagine is more significant to assess the characteristics of rainfall preceding landslide events recorded in historical inventory. According to [17] the established system can use both real time and forecasting rainfall data and can identify the most hazardous rainfall of each rain event. [18] defined that remote sensing satellite-based observation data can provide a solution for spatial sampling limitations of gauge-based gauge network. [19] suggested that satellite data can be used for forecasting landslides, only performing a local scaling between satellite and ground data. The increased availability, consistency and high-spatiotemporal-resolution of data is useful in landslide hazard assessment for broad-scale, global, regional, country and catchment-level and are not limited by inaccessibility due to terrain, culture and politics.

In this study, Ulu Kelang, Selangor was used as a case study to develop a RLEWS based on the relationship between rainfall and landslide occurences. The developed method is based on real time TRMM satellite data and rainfall threshold analysis, which is able to retrieve and store real time rainfall data for the landslide early warning system. The objective of this research was developing the low-cost and sustainable early warning system; and web based application to provide notification, awareness and landslide information for residential areas in Ulu Kelang, Selangor.

\section{METHODOLOGY}

\subsection{Study Area and Data}

RLEWS is developed for Ulu Kelang, Selangor with cover an area of 600 hectares. Ulu Kelang is located at the latitude of $3^{\circ} 12^{\prime} 30^{\prime}$ ' $\mathrm{N}$ and $101^{\circ} 45^{\prime} 28^{\prime}$ ' $\mathrm{E}$ with approximate distance of $5 \mathrm{~km}$ from Kuala Lumpur city centre as shows in Figure 1. Ulu Kelang is known as an urban area which having very high demand for its land, property and housing development in the hillside area. The climate of this area is commonly hot and humid as it is located in the tropical monsoon region.

The rainfall data which are used in the rainfall threshold analysis is obtained from TRMM satellite precipitation in gridded point located at the latitude of $3.125^{\circ} \mathrm{N}$ and $101.875^{\circ} \mathrm{E}$. In this study, TRMM Data product Daily Rainfall (TRMM_3B42_Daily v7) is applied in the rainfall analysis. Fourteen historical landslide location is selected to construct a rainfall threshold analysis in Ulu Kelang Selangor. The historical landslide event is occurring between years 1999 to 2012.

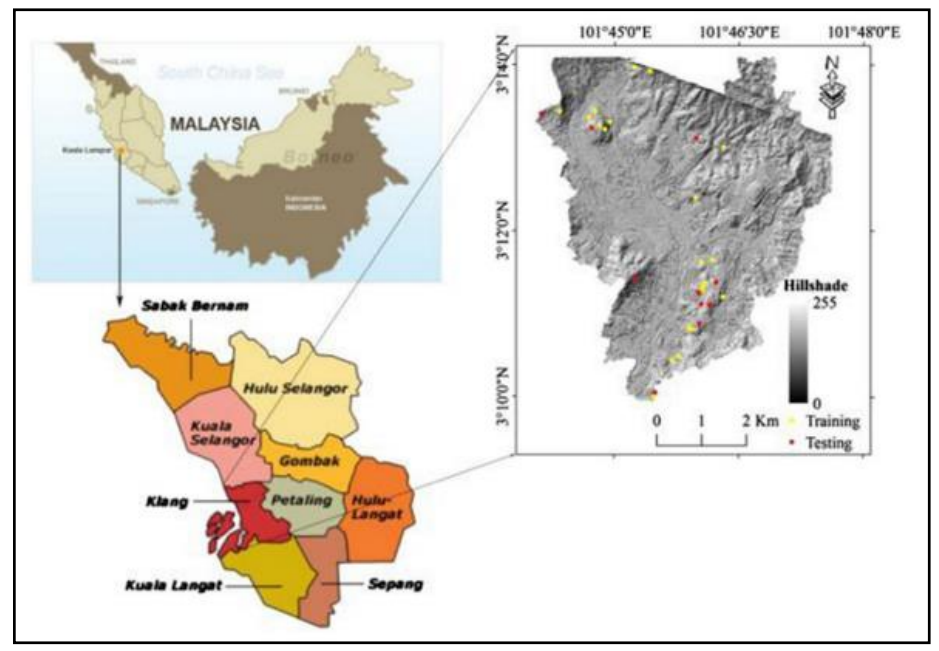

Figure 1. Location of Ulu Kelang, Selangor 


\subsection{Rainfall threshold analysis}

The rainfall threshold was developed to determine the amount of rainfall that, when reached or exceeded, is likely to trigger landslides. The threshold also interpreted as an approximate lower-bound threshold. Where is when below the specified level, the rainfall induced landslide activity does not occur, or rarely occurs, and above which it may occur under certain condition. In this study, the E3-E30 diagram is plotted to determine the rainfall threshold for Ulu Kelang, Selangor. The rainfall threshold was analyzed using TRMM Satellite data based on the historical landslide occurrence information since year 1999-2012.

The proposed rainfall threshold for landslide occurences in Ulu Kelang is constructed by plotted 3day and 30-day cumulative rainfall for fourteen selected landslide events. There are two categories of landslide events ; major landslide and minor landslide involve in the analysis to determine the warning level of potential landslide occurences. The plotted graph was formed of two limitation threshold line which is divided the warning level into three states, namely as low, moderate and high level of pontential landslide occurances. The rainfall threshold line in Figure 2 is shows the formed of proposed rainfall threshold for Ulu Kelang, Selangor. The rainfall threshold limitation line as following:

$$
\begin{aligned}
& \text { For major landslide: } E_{3}=161.71-0.607 E_{30} \\
& \text { For minor landslide: } E_{3}=110.02-0.607 E_{30}
\end{aligned}
$$

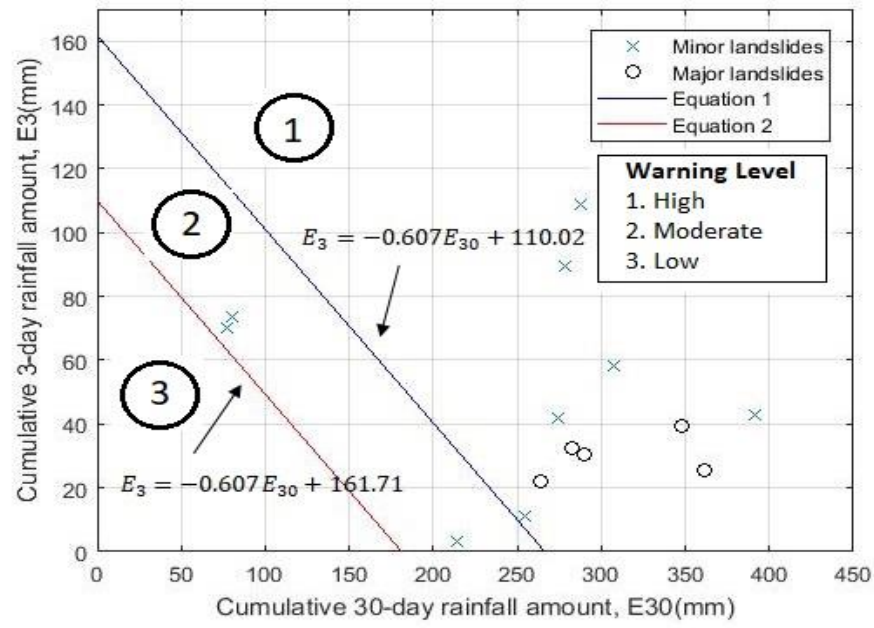

Figure 2. The Proposed Rainfall (E3-E30) Threshold Chart for Ulu Kelang, Selangor

\subsection{RLEWS Development}

RLEWS is a system which involves the analysis of rainfall data obtained from TRMM satellite precipitation estimates. One gridded point of TRMM data is required to represent the rainfall amount of landslide prone area in Ulu Kelang, Selangor. The rainfall data is available on the NASA Earth Data Network. The real time daily rainfall data is automatically retrieved from the NASA database to the RLEWS Web Server. Then the TRMM rainfall data are analyzed into three parameters; these are daily rainfall, 3 day accumulated rainfall and 30 day accumulated rainfall. All these parameters are plotted on a graph known as rainfall pattern analysis. The 3 day accumulated rainfall and 30 day accumulated rainfall parameters are required to identify the warning level of landslide occurrences by using rainfall threshold analysis. This analysis is a continuing process is where the system is updating the daily rainfall data every day. The flowchart diagram for RLEWS is shown in Figure 3. There are various information have is available to view for purpose of early warning signal for landslide occurrences and as well as the landslide monitoring tool. The Web-based interface can be displayed in desktop and mobile devices. 


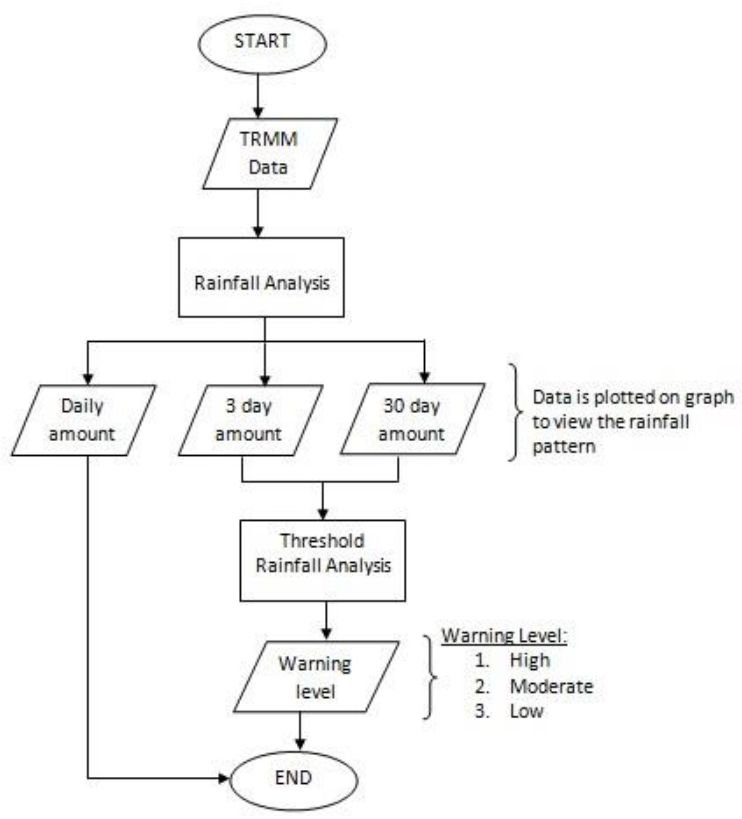

Figure 3. Flowchart for RLEWS

\subsection{RLEWS Web-based Interface}

RLEWS is a web-based interface of some related components. The RLEWS Web-based Interface is combination of rainfall analysis, computer programming and interconnected database. The PHP Java script is used to retrieve and extract data from the TRMM satellite database, identify the warning level by analyzing rainfall threshold and to provide others available real time information. The whole system is shown in Figure 4.

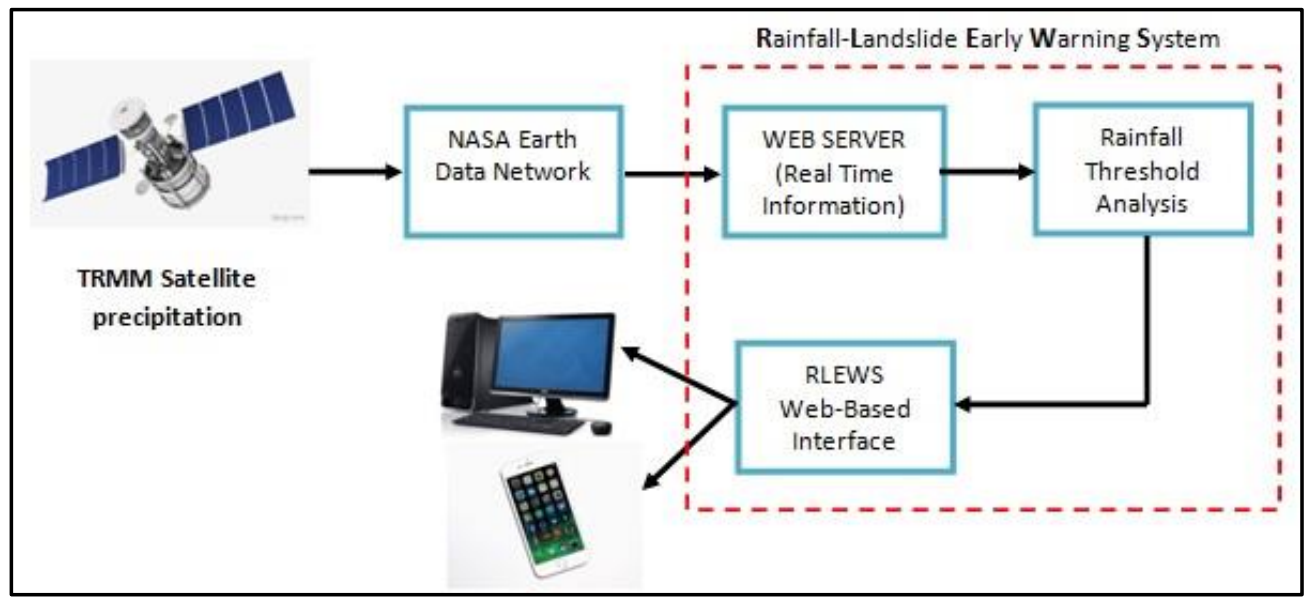

Figure 4. The RLEWS block diagram

\section{RESULTS AND ANALYSIS}

The Web-based Interface of RLEWS is divided into four informative sections, known as home, rainfall pattern, data management and about us. Each section provides the information and analysis, which including warning level, rainfall data, graph, table and explanation. All the information provided by RLEWS is used as early warning signal and monitoring tool for potential landslide.

Home is a front page which is viewed the warning signal level of potential landslide occurrences in Ulu Kelang, Selangor. In this section, the rainfall amount of daily rainfall, accumulated 3-day rainfall and 
accumulated 30-days rainfall are real time rainfall information to identify the warning signal level. This information can be viewed as shown in Figure 5. Figure 5 shows the rainfall information on $4^{\text {th }}$ September 2018. Where daily rainfall is $3.99 \mathrm{~mm}$, total 3 day rainfall is $22.08 \mathrm{~mm}$ and total 30 day rainfall is $44.16 \mathrm{~mm}$. While the warning level shows a low potential of landslide occurs

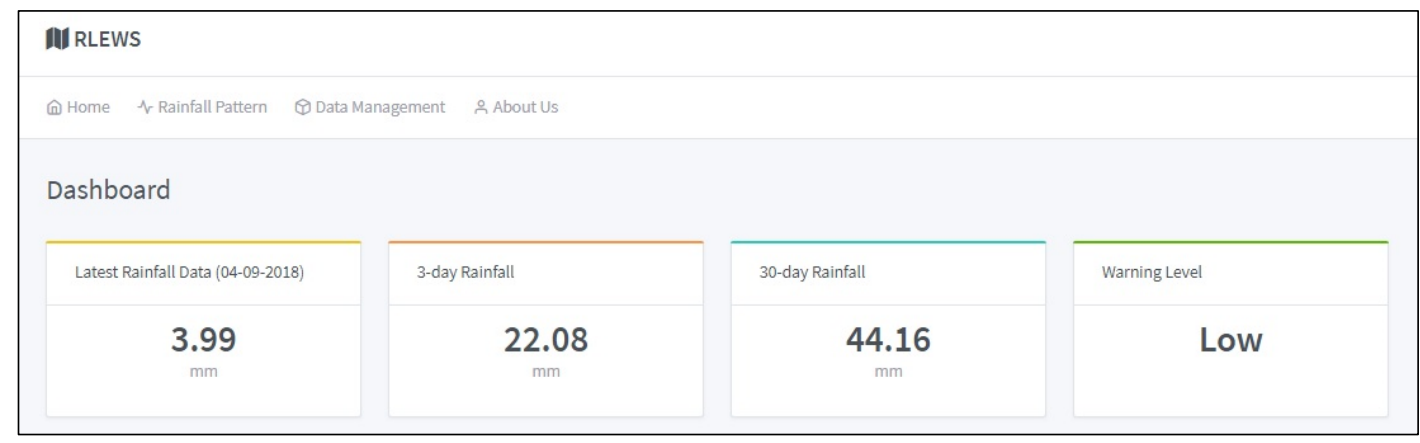

Figure 5. Real-time information: Daily rainfall, 3-day rainfall, 30-day rainfall and warning level

The plotted graph of rainfall threshold analysis of previous 30-day is shown in Figure 6. The graph can be used to monitor potential landslide occurrences based on rainfall data. The rainfall thresholds are divided into 3 areas of graph; which are high, moderate and low. The border of each area level is assigned by the green line for low-moderate limit and red line for moderate-high limit. The graph shows 30 points represent as a 30 days rainfall threshold analysis, where 29 points is located in the lower level area and 1 point is fall into the moderate level of potential landslide occurrences. The information about date, 3-day accumulated rainfall and 30-day accumulated rainfall for each rainfall threshold point can be appearing when cursor is appointed to the point.

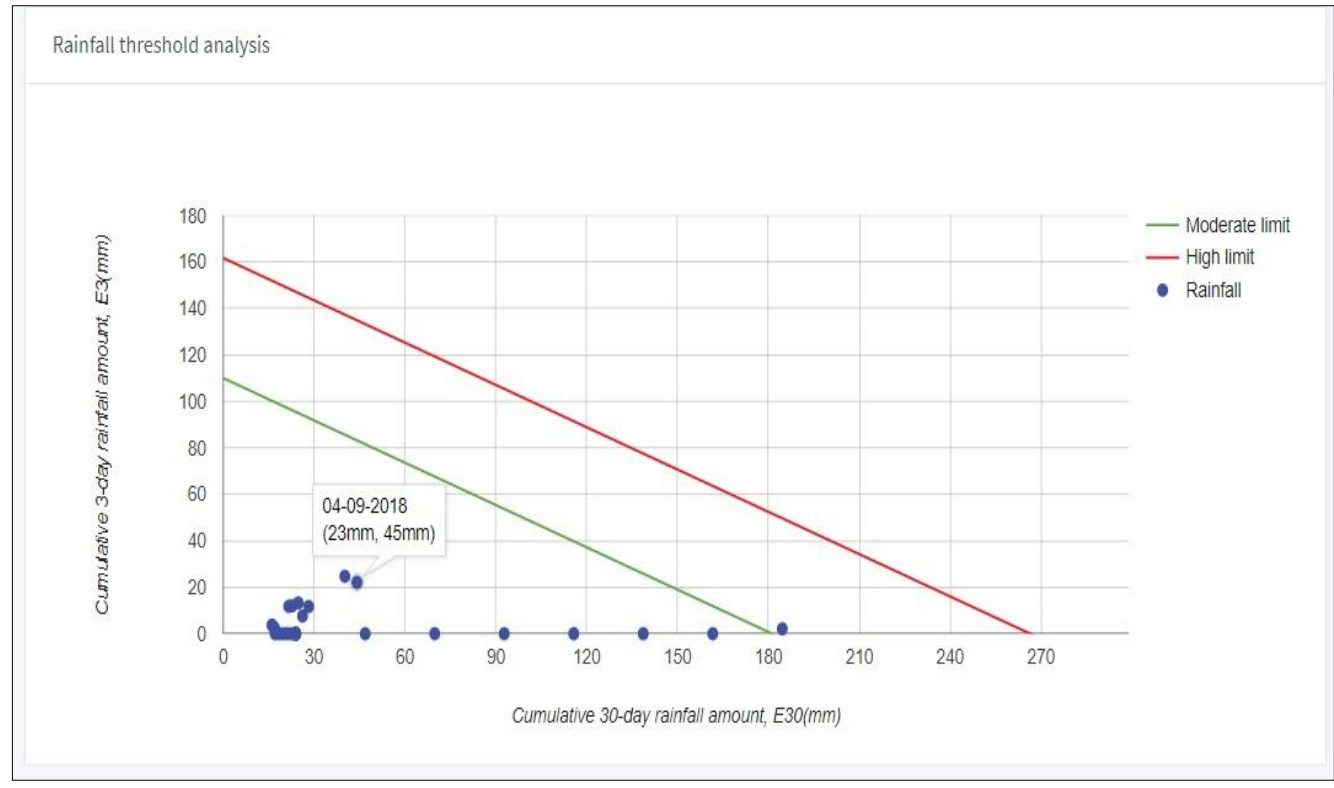

Figure 6. Rainfall threshold analysis view interface

The table of rainfall analysis in previous 30 days is provided to view the value of parameter such as date, daily rainfall, 3-day accumulated rainfall, 30-day accumulated rainfall and warning level. Figure 7 shows the sample 7-days of rainfall data analysis where all day are recorded at low warning level of potential landslide occurrences. 


\begin{tabular}{|c|c|c|c|c|c|}
\hline \multicolumn{6}{|c|}{ Rainfall data analysis } \\
\hline & Date & 1-day (mm) & 3-day (mm) & 30-day (mm) & Warning Level \\
\hline 1 & 04-09-2018 & 3.99 & 22.08 & 44.16 & 니표 \\
\hline 2 & $03-09-2018$ & 14.01 & 24.72 & 40.17 & Lom \\
\hline 3 & $02-09-2018$ & 4.08 & 11.7 & 28.23 & 다요 \\
\hline 4 & $01-09-2018$ & 6.63 & 7.62 & 26.22 & Lom \\
\hline 5 & $31-08-2018$ & 0.99 & 11.76 & 21.66 & Lom \\
\hline 6 & $30-08-2018$ & 0 & 12 & 22.74 & Lom \\
\hline 7 & $29-08-2018$ & 10.77 & 13.23 & 24.81 & Lom \\
\hline
\end{tabular}

Figure 7. Rainfall threshold analysis table view interface

In rainfall pattern section, three rainfall patterns were plotted using real time TRMM satellite data in previous 30-days. This information is useful for landslide monitoring based on rainfall pattern of daily rainfall, accumulated 3-day rainfall and accumulated 30-day rainfall. When the line graph is increasing, the potential landslide occurrences will be increased and need highly monitored by responsible agency and resident area. The real time rainfall pattern interface for 30 days in between $25^{\text {th }}$ August 2018 to $3^{\text {rd }}$ September 2018 is shown in Figure 8 and 9. In Figure 8(a) the maximum daily rainfall is recorded as $14.1 \mathrm{~mm}$ while minimum is $0 \mathrm{~mm}$. The graph shows that 21 days without rain and the remaining days are rainy day. According to [20], when the daily rainfall amount is more than $40 \mathrm{~mm}$, the potential landslide occurrences are increased.

In accumulated 3-day rainfall pattern shown in Figure 8(b), the maximum accumulated 3 day rainfall is $24.72 \mathrm{~mm}$. The minimum value is $0 \mathrm{~mm}$ and this value shown that the previous are 3 days without rain. The accumulated 3-day rainfall pattern is able to monitor the potential landslide occurs because of heavy raining in short duration rainfall period. Based on the study, the landslide occurrences were triggered when the amount of accumulated 3-day rainfall is reached $110 \mathrm{~mm}$ [20]. The rainfall pattern shown in Figure 9 is plotted to monitor the potential landslide occurred because of prolonged continuous rainfall. The rainfall threshold amount which reaches $300 \mathrm{~mm}$ to $450 \mathrm{~mm}$ can be triggered the landslide occurrences. $178 \mathrm{~mm}$ is recorded as a maximum amount of accumulated 30 day rainfall, while $20 \mathrm{~mm}$ is a minimum amount. That means each amount is recorded under the limitation of rainfall threshold of potential landslide occurrences.

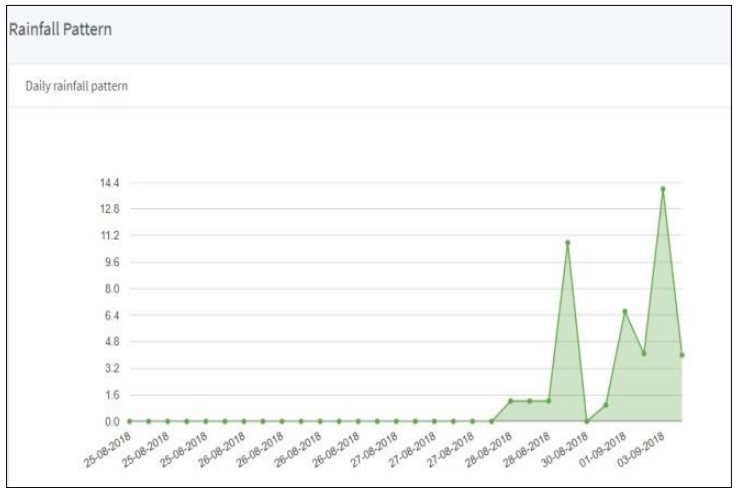

(a)

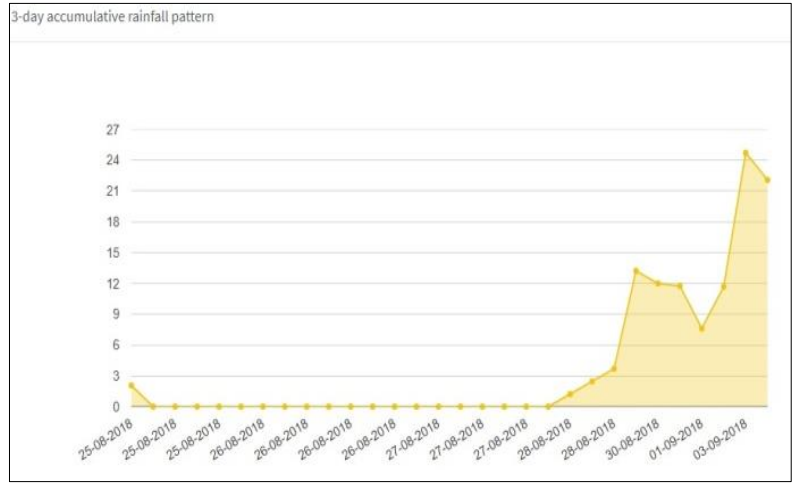

(b)

Figure 8 (a) Rainfall Pattern interface for Daily rainfall (b) Rainfall Pattern interface for 3-day accumulative rainfall 


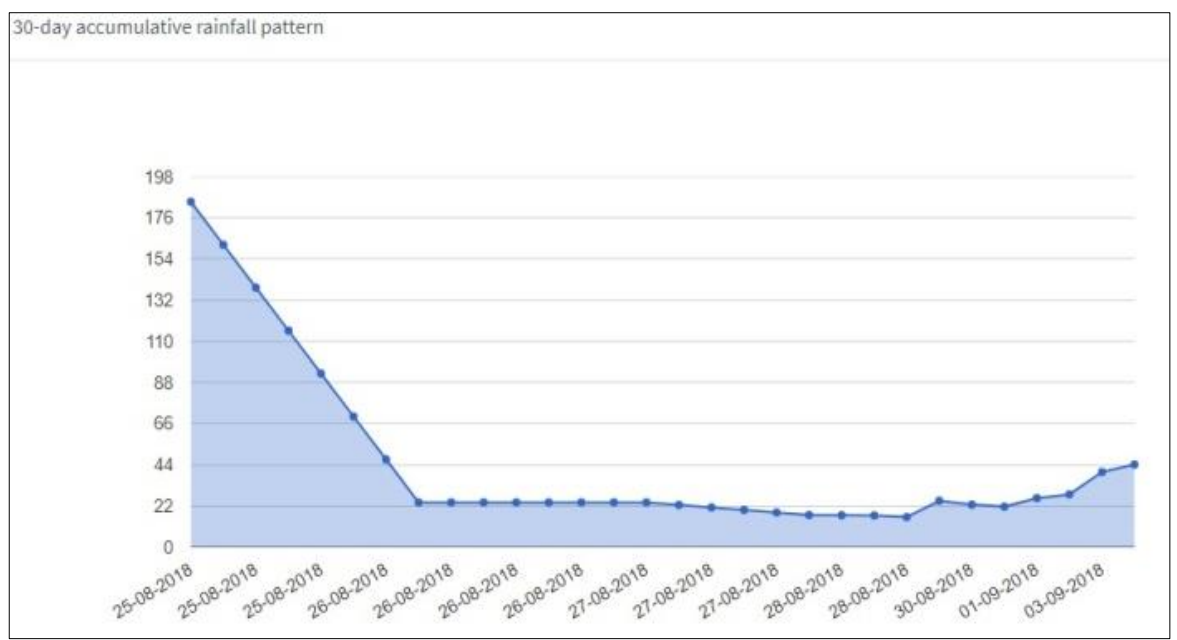

Figure 9. Rainfall Pattern interface for 30-day accumulative rainfall

\section{CONCLUSION}

RLEWS is implemented a real-time data to obtain more accurate analysis related to rainfall and landslide occurences. The main purpose of RLEWS is providing an early warning signal for potential landslide occurences. Besides that, the information and analysis in RLEWS Web-based intercafe can be applied as landslide monitoring tools for Ulu Kelang, Selangor. Three notification level of warning signal was introduced; high, modarate and low. The identification of warning level is based on rainfall threshold analysis of TRMM satellite data. The development of RLEWS is successful and the analysis information is updating in 24 hours which is benefit to community of residential area in Ulu Kelang, local authority such as MPAJ; and urban developer in providing notification, awareness and landslide information.

\section{ACKNOWLEDGEMENTS}

The authors would like to thank Faculty of Electrical Engineering, Universiti Teknologi MARA (UiTM) for their valuable support. This research is partly funded by the Malaysian Government through UiTM under 600-RMI/DANA5/3/BESTARI (122/2018). We are grateful to NASA TMPA for providing the TRMM product version 7 3B42 (7) data.

\section{REFERENCES}

[1] K. Zhang, et al., "The assessment of landslide susceptibility mapping using random forest and decision tree methods in the Three Gorges Reservior area, China," Environ Earth Sci., 2017.

[2] Kyungjin A., et al., "Developing an Accessible Landslide Susceptibility Model Using Open-Source Resources," Sustainability, vol. 10, pp. 293, 2018.

[3] F. Ferrigno, et al., "GB-InSAR monitoring and observational method for landslide emergency management:the Montaguto earthflow (AV,Italy)," Nat. Hazards Earth Syst. Sci., vol. 17, pp. 845-860, 2017.

[4] I. E. Samy, et al., "Landslide Modelling and Analysis using Remote Sensing and GIS: A case study of Cameron Highland, Malaysia," Journal of Geomatics ISG, vol/issue: 8(2), 2014.

[5] Y. Artha and E. S. Julian, "Landslide early warning system prototype with GIS analysis indicates by soil movement and rainfall," IOP Conf. Series: Earth and Environmental Science, pp. 106, 2018.

[6] Z. Liao, et al., "Prototyping an experimental early warning system for rainfall-induced landslides in Indonesia using satellite remote sensing and geospatial datasets," Landslides, vol/issue: 7(3), pp. 317-324, 2010.

[7] A. Rosi, et al., "Updating EWS rainfall thresholds for the triggering of landslides," Nat Hazards, 2015.

[8] A. Agostini, et al., "A new appraisal of the Ancona landslide based on geotechnical investigations and stability modeling," Journal of Engineering Geology and Hydrogeology, vol. 47, pp. 29-43, 2013.

[9] B. B. Mirus, et al., "Developing Hydro-Meteorological Thresholds for Shallow Landslide Initiation and Early Warning," Water, vol. 10, pp. 1274, 2018.

[10] C. F. Lee, et al., "Combining rainfall parameter and landslide susceptibility to forecast shallow landslide in Taiwan," Geotechnical Engineering Journal of the SEAGS \& AGSSEA, vol/issue: 47(2), 2016.

[11] E. Monsieurs, et al., "A susceptibility-based rainfall threshold approach for landslide occurrence," Nat. Hazards Earth Syst. Sci. Discuss, 2018.

[12] T. Vaz, et al., "Regional rainfall thresholds for landslide occurrence using a centenary database," Nat. Hazards Earth Syst. Sci., vol. 18, pp. 1037-1054, 2018. 
[13] A. Kassim, et al., "Modelling of suction distributions in an unsaturated heterogeneous residual soil slope," Engineering Geology, pp. 131-132, 2012.

[14] D. Kirschbaum and T.Stanley, "Satellite Based Assessment of Rainfall-Triggered Landslide Hazard for Situational Awareness," Earth's Future, vol. 6, pp. 505-523, 2018.

[15] M. T. Brunetti, et al., "How far are we from the use of satellite rainfall products in landslide forecasting?" Remote Sensing of Environment, vol. 210, pp. 65-75, 2018.

[16] B. G. Chae, et al., "Landslide prediction, monitoring and early warning: aconcise review of state-of-the-art," Geosciences Journal, vol/issue: 21(6), pp. 1033-1070, 2017.

[17] Rosi A., et al., "Definition of a fully functional EWS based on rainfall thresholds, the case of study of Tuscany Region," in Mikoš M., et al., "Advancing culture of living with landslides," Springer International Publishing, Switzerland, vol. 3, 2017.

[18] J. C. Robbins, "A probabilistic for assessing landslide-triggering event rainfall in Papua New Guine, using TRMM Satellite Precipitation estimates," Journal of Hydrology, vol. 541, pp. 296-309, 2016.

[19] M. Rossi, et al., "Comparison of Satellite Rainfall Estimates and Rain Gauge Measurements in Italy, and Impact onLandslide Modeling," Climate, vol. 5, pp. 90, 2017.

[20] N. Ya'acob, et al., "Rainfall thresholds for possible landslide occurrence in Ulu Kelang, Selangor, Malaysia using TRMM satellite precipitation estimates," IOP Conf. Ser.: Earth Environ. Sci., pp. 169, 2018. 